\title{
Anonymously male: Social media avatar icons are implicitly male and resistant to change
}

\author{
April H. Bailey, Marianne LaFrance \\ Department of Psychology, Yale University, New Haven, CT, United States
}

\begin{abstract}
When asked to pick a typical human, people are more likely to pick a man than a woman, a phenomenon reflecting androcentrism. Social media websites provide a relevant context in which to study androcentrism since many websites aim to provide users with an ostensibly gender-neutral icon if users do not upload one of their own images. In our first study, 50 male and female online participants $\left(M_{\text {age }}=35.70\right)$ rated whether actual avatar icons from highly trafficked social media websites are perceived as gender-neutral. Using bi-polar scales from woman to man participants reported that overall the icons appeared to be more male-typed than genderneutral. In Study 2, we investigated whether adding more female-typed icons would discourage or promote androcentric thinking. An online sample of 608 male and female participants $\left(M_{\text {age }}=33.76\right)$ viewed either 12 avatar icons that reflected the over-representation of male-typed icons or 12 that included an equal number of male and female-typed icons. Participants were then asked to produce an example of a typical person. Finally, we measured political ideology on two liberal-conservative scales. We found evidence that exposure to an equal number of male-typed and female-typed avatar icons generated reactance among political conservatives, and thus may have constituted an ideological threat. Conservatives who saw an equal number of male-typed and female-typed icons were twice as likely to come up with a man as a typical person compared to conservatives who saw an over-representation of male-typed avatar icons. Consistent with system-justification theory, these findings show how male-centric thinking is also evident in a seemingly gender-neutral online context.
\end{abstract}

Keywords: Social media; gender; avatars; system justification theory; threat

\section{Introduction}

Although men and women represent roughly equal portions of the population (Gao, 2015), men often emerge as the default human. For instance, when asked to select a typical individual from a broad, gender-inclusive population, people are more likely to select a man (Bailey \& LaFrance, 2016; Hamilton, 1991). Bem (1993) characterized this phenomenon as androcentrism.

Androcentrism refers to the tendency to view men as more normative or representative than women. Androcentric thinking is distinct from viewing men as being better or superior to women. While people regard men as better suited for many roles, specifically those requiring instrumental traits (Cejka \& Eagly, 1999; Eagly \& Karau, 2002; Heilman \& Eagly, 2008), androcentrism instead describes the belief that men are more typically human than women. Bem (1993) argues that male typicality affects perceptions across domains as men's bodies, thoughts, and experiences emerge as more normative relative to women's. 
Considerable research supports these claims (Broverman, Broverman, Clarkson, Rosenkrantz, \& Vogel, 1970; Lambdin, Greer, Jibotian, Wood, \& Hamilton, 2003; Sczesny, Formanowicz, \& Moser, 2016; Sczesny, Moser, \& Wood, 2015). For example, Hamilton (1991) asked participants to imagine the most typical person they could think of, give that person a name, and write about them. The majority of participants (75\%) generated a male example. Similarly, Eagly and Kite (1987) asked participants to rate a variety of nationalities on personality traits and characteristics. Some participants only rated men (e.g., British men), others only rated women (e.g., British women), and others only rated the gender unmarked nationality category (e.g., the British). Participants rated men and the unmarked nationality category more similarly than they did women and the unmarked nationality. The authors conclude that when participants considered the apparently unmarked nationality category, they were thinking about men more than women. In sum, people tend to think of men as typically representative of ostensibly gender-neutral categories.

Though subtle, androcentrism can have serious detrimental outcomes. It can contribute to errors in medical risk-assessment; much of the research on heart disease relies on male subjects and does not generalize when applied to female patients (Beery, 1995). Androcentrism can impact scientific inquiry more generally, causing researchers to chronically frame gender differences as women deviating from men regardless of the theoretical applicability of such framing (Cundiff, 2012; Hegarty \& Buechel, 2006; Miller, Taylor, \& Buck, 1991). Finally, androcentrism can limit women's representation. Androcentrism in employment and educational settings discourages women from pursuing those opportunities (Bem \& Bem, 1973; Stout \& Dasgupta, 2011) and discourages others from thinking of women as being suited for those positions (Stahlberg \& Sczesny, 2001, as cited in Sczesny et al., 2016). Given these consequential outcomes, it is important to understand how the tendency to think of men as more typical than women emerges even in contexts that are supposedly genderneutral.

The online environment provides an interesting context in which to investigate androcentrism as it allows for greater gender-neutrality. In face-to-face interactions, visible social identities like gender are salient and lead people to be treated differently based on their gender. In contrast, one of the hallmarks of online communication is its greater potential for anonymity and, by extension, gender-neutrality (Connolly, 2016). Greater gender-neutrality seemingly facilitates less gender bias. There is some evidence that online anonymity allows users to be evaluated based more on the merit of their contributions than on their social category memberships (equalizing hypothesis; Dubrovsky, Kiesler, \& Sethna, 1991). Given this, some users choose to deemphasize their gender category membership; female academics express hesitation about using an image of themselves in their professional online presence as doing so foregrounds gender (Miller \& Arnold, 2001). However, although some forms of gender bias may diminish in an online context due to greater genderneutrality (e.g., Dubrovsky et al., 1991), the very nature of androcentrism suggests that androcentrism would persist.

Research on androcentrism in gender-neutral language provides a point of comparison. Across a variety of languages, male-typed terms, he, man, and mankind, have been used gender-neutrally to refer to everyone (Hellinger \& Motschenbacher, 2015). Taken as an example of androcentrism, these male-typed terms also encourage other behaviors that reflect androcentrism. The neutral use of male-typed terms causes people to be even more likely to think of men compared to women as being typically representative of gender-neutral categories (Gastil, 1990; Hyde, 1984; Miller \& James, 2009; Ng, 1990; Schneider \& Hacker, 1973; Silveira, 1980; Switzer, 1990). Thus, supposedly neutral language that emphasizes men leads to more androcentric thinking. In response, many publishers now discourage the gender-neutral use of male-typed terms (e.g., American Psychological Association, 1978). However, recent work suggests that androcentrism is so deeply embedded that even unmarked representations that deemphasize gender may not be enough to offset androcentric thinking.

Bailey and LaFrance (2016) presented participants with a collection of headshots of men and women and asked participants to select a single image to represent humanity to a hypothetical alien race. The term used to describe humanity varied: male-typed (mankind), unmarked (human), or both gender-typed (man or woman). We found that the male-typed mankind condition and the unmarked human condition led more participants to select a man relative to the gender-typed man or woman condition. Consistent with previous work on the limitations of bias-reduction language interventions (Prentice, 1994), this finding reflects the deeply embedded nature of androcentrism. The unmarked term human led to similar results as the male-typed term mankind. Thus 
supposedly gender-neutral representations that deemphasize gender still led to behaviors consistent with androcentrism.

The online context allows people to curate their identities to a greater degree than in-person interactions (Connolly, 2016). Online, people can decide to deemphasize their gender by using gender-neutral representations. Various social media websites allow users to represent themselves in a relatively unmarked fashion. When users do not upload their own image to represent themselves, many websites assign users an ostensibly gender-neutral default icon, either of a symbol or of a human silhouette. These default avatar icons are seemingly gender-neutral. However, the research on androcentrism shows that people perceive unmarked words as being more male-typed than not (e.g., Bailey \& LaFrance, 2016; Hamilton, 1991). Thus, unmarked avatar images may also be perceived as being more male-typed than not, thus perpetuating androcentrism.

In sum, androcentrism is a pervasive ideological system that positions men as more representative or typical than women (Bem, 1993), and the generic use of male-typed language serves to perpetuate this status quo (e.g., Miller \& James, 2009). Recent work indicates that even unmarked terms, specifically human, lead to androcentric choices (Bailey \& LaFrance, 2016). Thus, androcentrism emerges even in contexts that de-emphasize gender. The online environment de-emphasizes gender by allowing for greater gender-neutrality than face-to-face interactions. In the past ten years the percentage of adults who use social media has augmented nearly tenfold (Perrin, 2015). Thus, understanding if and how androcentrism emerges in the online environment becomes all the more important. In the current studies, we focused on social media avatar icons, many of which stand in as gender-neutral representation of users. The current studies investigated whether unmarked icons in online contexts reflect an androcentric bias (Study 1) and what effect gender-typed icons have on users (Study 2).

\section{Study 1}

\section{Present Study}

Study 1 investigated whether people perceive the default avatar icons from highly trafficked social media websites to be gender-neutral. We asked participants to indicate the degree to which each of several icons appeared to be of a man or a woman on a bi-polar scale with the option of indicating that the image was genderneutral. Thus, we were interested in the perceived gender category of the icons, rather than their masculinity or femininity. We predicted that participants would be more likely to view the icons as male-typed (e.g., Bailey \& LaFrance, 2016).

Hypothesis 1: Participants will perceive unmarked icons as being more male-typed than neutral.

\section{Methods}

Participants. Using Amazon's MechanicalTurk platform, 50 individuals $\left(M_{\text {age }}=35.70, S D_{\text {age }}=10.41 ; 24\right.$ women, 33 white, 4 black, 4 east Asian, and 9 of other races and ethnicities) completed the online survey and were compensated $\$ 0.40$. No individuals were excluded as all passed our pre-determined attention monitoring checks. Median completion time was three minutes. The Yale Human Subjects Committee (YHSC) reviewed Study 1 and Study 2 and determined both to be exempt from further review.

Materials and procedure. Avatar icons were selected from the nine most popular social media websites identified by the Pew Research Center among teens and adults as of 2013: Facebook, Twitter, Vine, Instagram, Google+, Linkedln, Snapchat, Tumblr, and Pinterest (Duggan \& Smith, 2013; Lenhart, 2015). Two new accounts were created for each website, one indicating the user's gender as a woman and the other as a man. As of 2015, only one website, Facebook, automatically assigned a different icon based on self-identified gender. This resulted in 10 distinct icons. Of this set, the Facebook icons are unique in that they are intended to be gendertyped. The other eight are ostensibly gender-neutral.

After agreeing to participate, participants viewed a series of individual images. For each avatar image, they were asked to rate, "the degree to which each appears to be of a man or a woman...if the image appears to be equally of a man or a woman, place the slider at 50." We opted for a single scale with man and woman at opposite ends 
because gender is usually viewed as binary by the lay public (Reis \& Carothers, 2014). Participants then saw each avatar image presented in a random order and indicated the gender of the image on a slider from woman (0) to man (100). ${ }^{1}$ The slider starting position was always at neutral (50).

Participants then filled out demographic items and a four-item measure of gender polarization (Burke \& LaFrance, 2016), which is not discussed further. Finally, we asked participants to guess the purpose of the study. No participants correctly identified the hypothesis.

\section{Results}

Supporting $\mathrm{H} 1$, on average the icons were rated as being more male-typed than neutral (50) using one-sample ttests. This was true both concerning the average of all ten icons $(M=56.74, S D=6.27), t(49)=7.60, p<.001,95 \%$ $\mathrm{Cl}[4.96,8.51]$ and with the gender-typed Facebook icons removed $(M=58.48, S D=7.89), t(49)=7.60, p<.001$, $95 \% \mathrm{Cl}[6.23,10.72]$.

We also considered the ratings for each icon separately and employed a Bonferroni correction for multiple comparisons (Figure 1; see Table 1 for statistics; Dunn, 1961). Unsurprisingly, the female-typed and male-typed Facebook icons were rated as more female-typed than neutral and more male-typed than neutral respectively. Three icons were rated as more male-typed than neutral. The remaining five icons did not differ significantly from neutral.

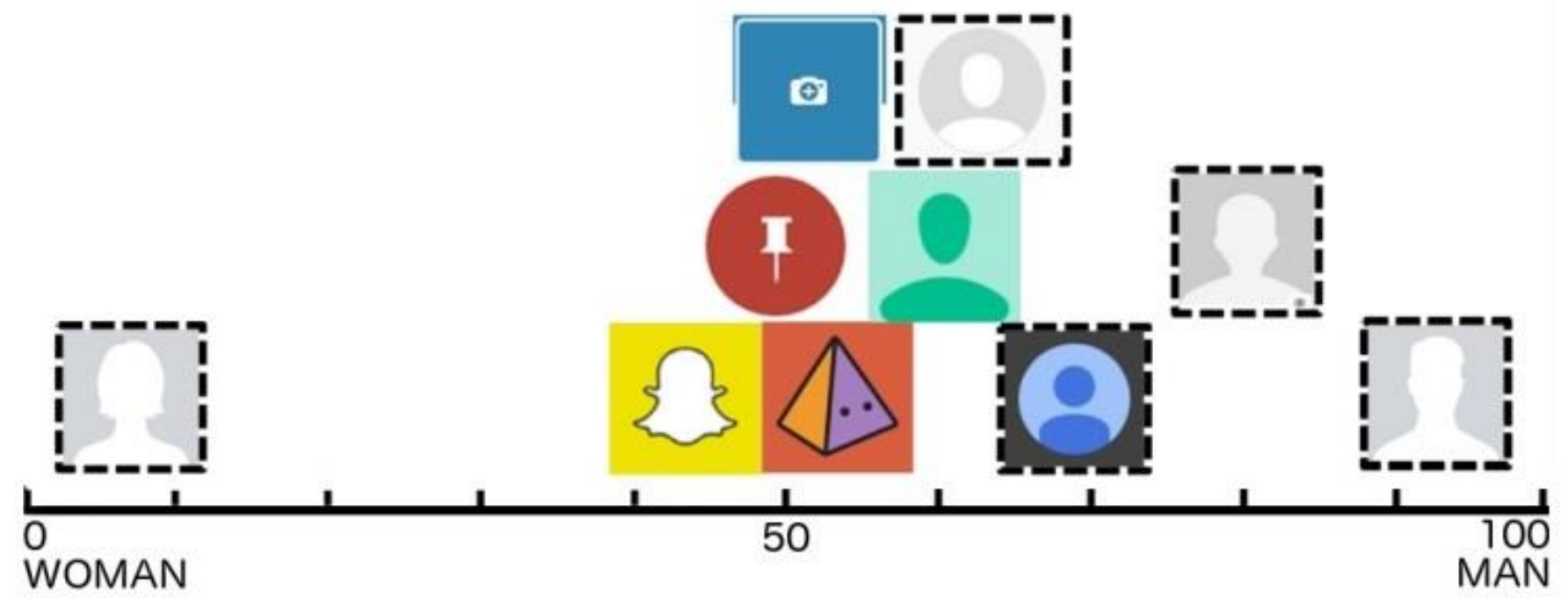

Figure 1. In Study 1, the average placement of each of the icon images on a scale from woman (0) to man (100). Images significantly different from neutral (50) are indicated with a dashed outline, Bonferroni corrected $p<.005$

(Dunn, 1961).

Table 1. Difference from Neutral (50) for each Individual Avatar Icon in Study 1.

\begin{tabular}{lcccc}
\hline Avatar & Mean (SD) & $\mathbf{t}(\mathbf{4 9 )}$ & $\boldsymbol{p}$ value & $\mathbf{9 5 \%} \mathbf{C l}$ \\
\hline Facebook female & $7.12(12.99)$ & -23.34 & $<.001^{*}$ & {$[-46.57,-39.19]$} \\
Snapchat & $43.32(17.91)$ & -2.64 & .011 & {$[-11.77,-1.59]$} \\
Pinterest & $48.84(16.28)$ & -0.50 & .617 & {$[-5.79,3.47]$} \\
Twitter & $51.10(11.57)$ & 0.67 & .504 & {$[-2.19,4.39]$} \\
Tumblr & $53.42(13.47)$ & 1.80 & .079 & {$[-0.41,7.25]$} \\
Vine & $59.52(24.18)$ & 2.78 & .008 & {$[2.65,16.39]$} \\
Instagram & $62.52(21.52)$ & 4.11 & $<.001^{*}$ & {$[6.40,18.64]$} \\
Google+ & $68.98(23.62)$ & 5.68 & $<.001^{*}$ & {$[12.27,25.69]$} \\
Linkedln & $80.12(19.49)$ & 10.93 & $<.001^{*}$ & {$[24.58,35.66]$} \\
Facebook male & $92.44(12.88)$ & 23.29 & $<.001^{*}$ & {$[38.78,46.10]$} \\
\hline
\end{tabular}

Note: * significant at $p<.005$, reflecting a Bonferroni correction for multiple comparisons (Dunn, 1961) 
We considered whether participant gender moderated these effects using an analysis of variance (ANOVA) with participant gender as the single factor. There was no evidence that male and female participants' ratings differed either concerning the average rating of all icons, $F(1,48)=0.63, p=.430, \eta_{p}^{2}=0.01$, or with the Facebook icons removed, $F(1,48)=0.77, p=.384, \eta_{p}^{2}=0.02$.

\section{Discussion}

All nine of the highly trafficked social media websites investigated here provide users with a default icon if they chose not to upload their own image. However, participants did not perceive all of these icons as gender-neutral but instead saw some as being more male-typed.

There are two plausible reasons for the observed findings. Androcentrism may influence the nature of the icons and participants are merely reporting it. Thus, androcentrism could be embedded in particular features of the icons; for instance, the icons that tended to be rated as gender-typed also tended to be less colorful. Alternatively, participants' ratings may reflect androcentric perceptions. Thus, the icons themselves may have been gender-neutral and the ratings merely show participants' own androcentric biases.

Whichever explanation is correct, and both may be involved, it remains that the current state of social media websites' icons reflects androcentrism. The perceived over-representation of male-typed icons compared to female-typed icons illustrates the general tendency to view a man as a typical person (Hamilton, 1991). Study 2 investigated the impact of this male-bias in social media icons on people's subsequent tendency to make an androcentric choice.

\section{Study 2}

\section{Present Study}

The over-representation of male-typed icons found in Study 1 may perpetuate a male-centric bias. Accordingly, an increase in female-typed icons could conceivably counter this bias; interventions that expose people to exemplars that defy the status quo can lead to a reduction in stereotyping (Dasgupta \& Greenwald, 2001; Finnegan, Oakhill, \& Garnham, 2015; Lai et al., 2014). The presence of more female-typed default icons alongside male-typed default icons could potentially encourage people to view both a man and a woman as equally representative.

System-justification theory (SJT) would instead suggest that an increase in female-typed icons could generate reactance. SJT argues that once people belong to a system they are motivated to support it even when they are directly harmed by it (Glick \& Fiske, 2001). This is particularly true of people high in political conservatism as they are especially motivated to maintain the status quo and resist change (Jost, Glaser, Kruglanski, \& Sulloway, 2003; Jost, Banji, \& Nosek, 2004). Even small changes can constitute a system stability threat, leading to status-quo consistent behavior (Kay \& Friesen, 2011; Kay, Jost, \& Young, 2005). Since increasing the representation of female-typed icons constitutes a change to the status quo found in Study 1, more female-typed icons could lead to reactance and even more male-centric thinking (Jost \& Banaji, 1994; Jost et al., 2004; Jost et al., 2003).

To consider these possibilities, we presented participants with default avatar icons that either resembled the status quo representation found in Study 1 by showing only a single female-typed icon alongside a collection of male-typed and neutral icons or a collection of icons that included more female-typed versions, along with fewer male-typed icons and the same number of neutral icons. We assessed androcentric behavior by asking participants to produce a typical person, which was then coded for gender. We expected that participants would be more likely to generate a man as a typical person and that this would be more pronounced among male participants; previous work using similar measures finds these effects (Bailey \& LaFrance, 2016; Gastil, 1990; Switzer, 1990). Finally, we had two opposing hypotheses contingent on whether the inclusion of more femaletyped exemplars inspired less androcentrism or constituted a system-stability threat leading to more androcentric tendencies. 
Hypothesis 1: Participants will be more likely to produce a man as a representative person relative to chance.

Hypothesis 2: Male participants will be more likely to produce a man as a representative person relative both to chance and to female participants.

Hypothesis 3: A) Participants exposed to more female-typed icons will be less likely to produce a man.

B) If however, more female-typed icons constitute a system-stability threat, participants, particularly political conservatives, exposed to a condition with more female-typed icons will be even more likely to produce man as a typical person.

\section{Methods}

Participants. Using Amazon's MechanicalTurk platform, 608 individuals completed the online survey and were compensated $\$ 0.50$. We subsequently excluded 24 individuals for failing pre-determined attention monitoring checks by indicating, for instance, two different ages. Further, we excluded 23 individuals whose responses were ambiguous, described in detail below. ${ }^{2}$ This resulted in 561 participants $\left(M_{\text {age }}=33.76, S D_{\text {age }}=10.01 ; 269\right.$ women, 1 transgender individual, 418 white, 57 East Asian, 40 black, 21 Hispanic or Latino, and 20 of other races and ethnicities). Median completion time was six minutes.

Avatar icon matrices. There were two icon conditions, a status quo condition and a more-female typed condition (Figure 2). The status quo condition had the proportion of gender-typed icons that resembled the status quo as indicated in Study 1: one female-typed icon, seven male-typed icons, and four neutral icons. The more-female typed condition constituted a change from the status quo by having the same number of femaletyped and male-typed icons: four female-typed icons, four male-typed icons, and four neutral icons. Thus, each icon set constituted 12 images in a $3 \times 4$ grid. These matrices were scrambled; the position of each icon in the grid was determined randomly for each participant.

In order to create the icon matrices, we used some of the icons from Study 1 and collected six additional icons from social media websites. This was done because the set of icons from Study 1 was limited in size and only included a single female-typed icon. In a pilot study, ten unique participants provided ratings of these 15 icons: four ostensibly gender-neutral icons, four ostensibly female-typed icons, and seven ostensibly male-typed icons. We used the same method as in Study 1, with the exception that we also allowed participants to check a box indicating that the icon was of a non-human symbol and thus gender-ratings did not apply.

For the ostensibly gender-neutral icons, Snapchat, Twitter, Tumblr, and Pinterest, a majority of the pilot participants (67\%) indicated that the avatars did not have any gender, $\chi^{2}(1, n=9)=8.33, p=.040, \phi_{c}=0.96$, and the remaining participants did not rate them as being different from neutral $(M=52.75, S D=5.43), t(2)=0.88, p=$ $.473,95 \% \mathrm{Cl}[-10.72,16.23]$. For the ostensibly female-typed icons, Facebook, Goodreads, Security Service, and Tagged, pilot participants rated them on average as being significantly more female-typed than neutral $(M=$ $18.92, S D=10.41), t(8)=-8.96, p<.001,95 \% \mathrm{Cl}[-39.08,-23.08]$. For the ostensibly male-typed icons, Facebook, Goodreads, Security Service, Skype, Google+, LinkedIn, and Instagram, pilot participants rated them on average as being significantly more male-typed than neutral $(M=76.04, S D=11.08), t(8)=7.04, p<.001,95 \% \mathrm{Cl}[17.52$, 34.55]. For the male-typed icons, this was true when considering only the sub-set of four icons, Skype, Google+, LinkedIn, and Instagram, that were shown in the more female-typed condition $(M=73.57, S D=10.44), t(8)=6.78$, $p<.001,95 \% \mathrm{Cl}[15.55,31.60]$. Thus, we confirmed our a priori classification of the icons as either being genderneutral, female-typed, or male-typed.

In order to generate enough female-typed icons, it was not possible to exclusively use icons from highly trafficked websites as in Study 1 . However, we held website popularity constant across icon matrix conditions by using icons from the same 12 websites in both. In the more female-typed condition, three of the female-typed icons were from the same websites as three of the male-typed icons in the status quo condition. For instance, in the more female-typed condition we used the female-typed Facebook icon while in the status quo condition we 
used the male-typed Facebook icon. Further, we measured familiarity with the icons by asking participants to indicate which icons they were "confident they had seen before." Familiarity ratings did not differ between the two conditions (status quo: $M=3.59, S D=1.87$, more female-typed: $M=3.77, S D=1.93$ ), $t(542)=1.10, p=.272$, $95 \% \mathrm{Cl}[-0.50,0.14]$.

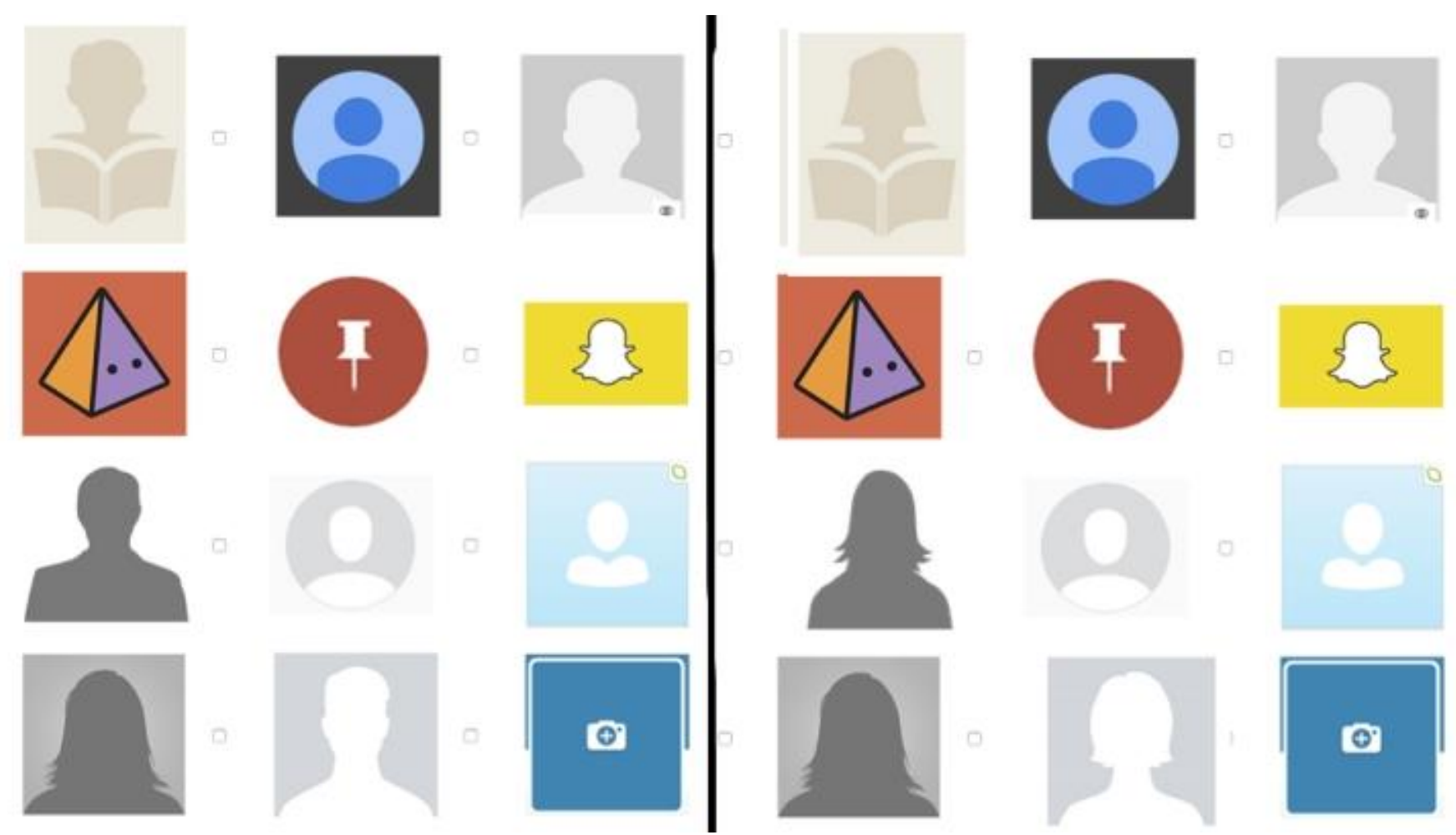

Figure 2. In Study 2, the avatar icon matrix in the status quo condition (left) and in the more female-typed condition (right). Both conditions depicted icons from the same 12 websites; we varied the number of maletyped and female-typed icons. For each participant, the matrix was scrambled; thus, the position of each icon in the grid was determined randomly.

Measure of androcentrism. We modeled our measure of androcentrism after Hamilton (1991). We prompted participants to "imagine a typical person (do NOT use yourself)" and asked them to give that person a name and a hobby. On the next page, participants indicated the gender of this person; they could indicate that they did not consider gender in their selection or had imagined someone who was transgender; eight participants who did so were excluded from subsequent analyses. Thus, the dependent measure was the gender of the imagined typical person, either a man or a woman.

To establish reliability, we compared the gender indicated by participants to the gender indicated by independent coders based on the name participants provided. This was done to rule out the possibility that participants changed their responses due to social desirability concerns once gender became salient. Recall that participants provided a name before indicating a gender. Two coders, blind to condition and blind to the gender that the participants provided, viewed the name and hobby of each typical person and assigned gender accordingly as male, female, or impossible to tell. Cohen's $k$, which adjusts for agreement due to chance, indicated almost perfect agreement $(\mathrm{K}=0.90)$; disagreements were resolved through discussion (Hallgren, 2012). We excluded the 15 participants for whom there was a discrepancy between the gender indicated by the participant and that indicated by the coders.

Political ideology. We measured participants' political ideology using two items that were randomly placed among other demographic questions. On a scale from very conservative (1) to very liberal (7), we asked participants "what is your political stance on economic issues broadly?" and "what is your political stance on social issues broadly?" These two items were correlated and combined into a single index, $r(556)=0.69, p<.001$. 
Participants' political ideology did not differ between the icon matrix conditions (status quo: $M=4.74, S D=1.50$, more female-typed: $M=4.82, S D=1.54), t(557)=0.64, p=.523,95 \% \mathrm{Cl}[-0.34,0.17]$.

Procedure. After consenting to participate, participants read that social media websites sometimes provide default avatar images to represent users who do not upload their own image. Participants then saw one of two avatar icon matrices, status quo or more female-typed. To ensure adequate attention to the icons, participants were asked to indicate which icons they were "confident they had seen before." Participants then answered distractor questions including their memory for the icons they had just seen. We also asked participants how much they identified with a variety of gender-related personality traits. The icon matrix condition had no impact on these identification ratings, which are not discussed further. Next, we measured androcentrism as described above. Finally, participants completed demographic items, including political ideology, and were asked to guess the purpose of the study. No participants correctly identified any of the hypotheses.

\section{Results}

In support of $\mathrm{H} 1$, participants were more likely to produce a man (69\%) than a woman as a typical person, $\chi^{2}(1, n$ $=561)=93.48, p<.001, \phi_{c}=0.41$. To test whether male participants were more likely to produce a man relative both to chance and to female participants, we conducted a logistic regression model with chi-squares to indicate differences from chance. Supporting $\mathrm{H} 2$, male participants (93\%) were more likely than female participants (46\%) to produce a man, $B=2.77, S E=0.26, p<.001$, odds ratio $(O R)=16.02$. Further, while male participants differed from chance, $\chi^{2}(1, n=290)=215.52, p<.001, \phi_{c}=0.86$, female participants did not, $\chi^{2}(1, n=269)=1.97, p=.161$, $\phi_{c}=0.09$ (Figure 3).

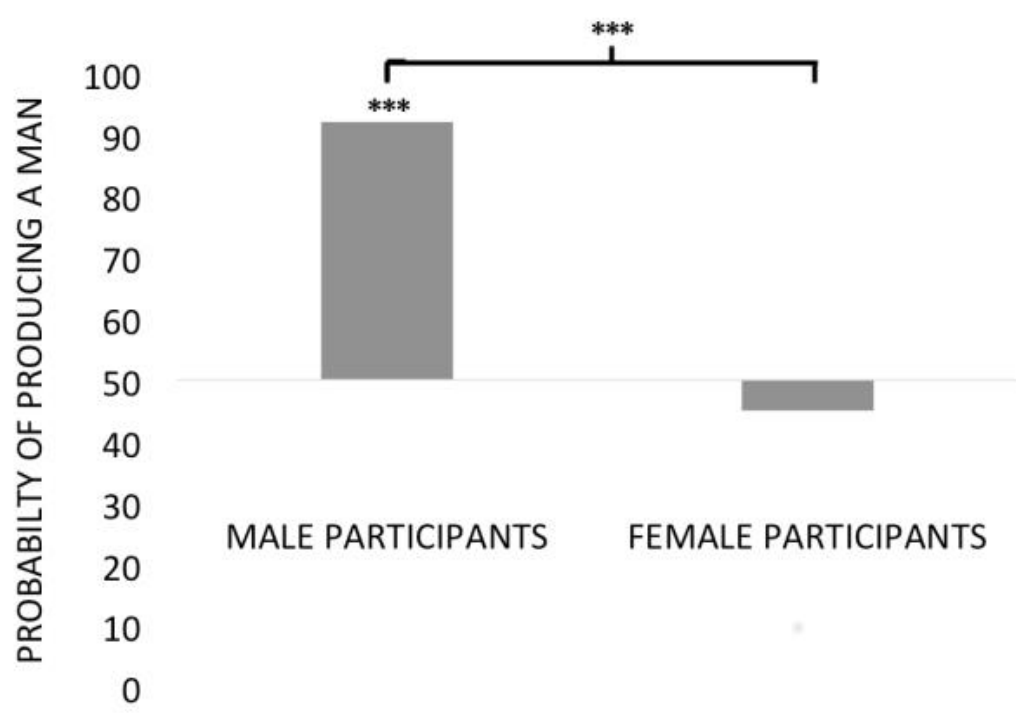

Figure 3. In Study 2, male participants were more likely to produce a man, both relative to chance and relative to female participants, $* \star * p<.001$.

To test whether exposure to more female-typed icons and political ideology affected participants' likelihood of producing a man as a typical person, we conducted logistic regressions after centering political ideology $(M=$ $4.78, S D=1.52$; Aiken \& West, 1991). Experimental condition significantly interacted with political ideology, $B=$ $0.27, S E=0.13, p=.033, \mathrm{OR}=1.32$ (Figure 4). Providing support for $\mathrm{H3B}$, among more politically conservative participants (-1SD), the more female-typed icon condition increased the likelihood that participants produced a man as a representative "person" (81\%) compared to the status quo condition (68\%), $B=0.71, S E=0.29, p=.014$, $\mathrm{OR}=0.49$. Among more politically liberal participants (+1SD), the more female-typed condition (65\%) had no effect compared to the status quo condition (68\%), $B=0.13, S E=0.26, p=.625$, OR $=1.13$. Thus, H3B was supported in favor of $\mathrm{H} 3 \mathrm{~A}$. 


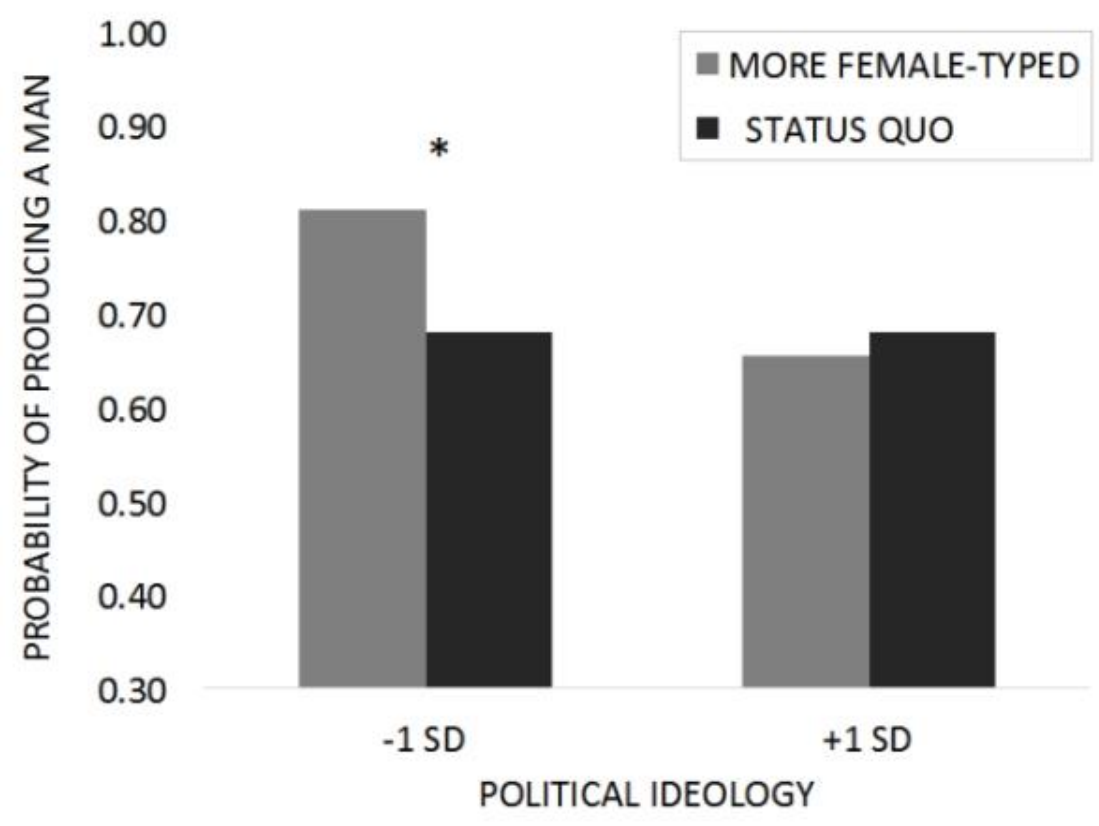

Figure 4. In Study 2, politically conservative participants (-1 SD) were twice as likely to produce a man in the more female-typed condition compared to the status quo condition. For politically liberal participants (+1 SD), condition had no effect, * $p<.05$.

Note that despite the participant gender differences in the overall likelihood of producing a man as a typical person, there was no evidence that the effect of political ideology was due to participant gender differences. There was no evidence that male and female participants differed in political ideology, $t(556)=1.40, p=.163$, $95 \% \mathrm{Cl}[-0.43,0.07]$, or that participant gender moderated the interaction between political ideology and condition, $B=0.09, \mathrm{SE}=0.35, p=.811$, $\mathrm{OR}=0.92$.

\section{Discussion}

An intuitive way to counteract androcentrism online would be to increase the number of female-typed icons for popular social media websites (e.g., Dasgupta \& Greenwald, 2001). In contrast, SJT would predict that such a change might constitute a system stability threat, causing people, particularly political conservatives, to engage in system supportive behaviors (Jost et al., 2004). In the present study we presented participants with a collection of icons that either resembled the status quo or changed it. Overall, participants, particularly male participants, were more likely to produce a man as a typical person. However, both male and female political conservatives exposed to more female-typed avatars were even more likely to produce a man as their typical person. Political liberals were unaffected. Thus, a simple way to combat androcentric thinking by increasing the salience of female-typed icons backfired and actually led to evidence for even more androcentric thinking among political conservatives and no significant evidence for change among political liberals.

\section{General Discussion}

Many social media websites assign users a default, gender-neutral avatar icon if users do not provide their own image. Study 1 showed that on average people perceive the default icons from highly trafficked social media websites as being more male-typed than gender-neutral.

Study 2 investigated whether exposure to more female-typed icons would counteract androcentric tendencies or confirm them as SJT would predict. Supporting the latter possibility, political conservatives exposed to more female-typed icons were even more likely to produce a man as a typical person. This change was not trivial. Exposure to female-typed icons made political conservatives (-1SD) twice as likely to produce a man (OR=2.01). 
This suggests that the addition of more female-typed icons alongside male-typed and neutral icons constituted a threat to system stability, causing those who are particularly committed to the system, namely political conservatives, to be more likely to behave in system-consistent ways.

These studies also provide insight into the role of participant gender. Study 2 found that while participants were more likely to produce a man as a typical person, it was male participants that drove this effect. Previous work that asked participants to pick or generate examples also finds that male participants are more likely to show male-favoritism (Bailey \& LaFrance, 2016; Gastil, 1990; Switzer, 1990). However, although participant gender seems to make a difference for these more explicit tasks, it has less of an impact for more subtle trait rating tasks or when rapid responses are emphasized (Broverman et al., 1970; Eagly \& Kite, 1987; Miller \& James, 2009). Thus, participant gender did not moderate the ratings of the avatars in Study 1 but did affect participants' likelihood of generating a man as a typical person in Study 2. Importantly, both male and female participants high in political conservatism responded to more female-typed icons with status quo consistent behavior. This is unsurprising given that SJT and related empirical work shows that even individuals who are systematically disadvantaged by the status quo, in this case women, will endorse it (Glick \& Fiske, 2001; Jost et al., 2004).

As social media websites become increasingly important in contributing to societal norms, investigating the unique ways that they can perpetuate androcentrism is crucial. Although the online context seemingly enables greater gender-neutrality and a reduction in some forms of gender bias (Dubrovsky et al., 1991), Studies 1 and 2 provide evidence for androcentrism and suggest moreover that it is resistant to change. Bias-reduction interventions can backfire and produce the exact outcome they are designed to combat (e.g., Forsyth, Lawrence, Burnette, \& Baumeister, 2007; Legault, Gutsell, \& Inzlicht, 2011; Roussos \& Dovidio, 2016; Vorauer \& Sasaki, 2009). That appears to be the case here. In Study 2, a transient exposure to an equal number of female-typed and male-typed icons constituted a system stability threat among political conservatives leading to behavior that further reified androcentrism rather than disrupting it.

\section{Limitations and Future Directions}

The avatar icons used in both Studies 1 and 2 were extracted from existing websites and have idiosyncratic features. Although this allows for greater generalizability, it also limits some experimental control. Study 1 shows that more icons were rated as male-typed than female-typed, but it does not show what features of the avatar images might have caused this bias. Colorful icons depicting non-human symbols tended to be rated as more gender-neutral; gray avatar images of human silhouettes tended to be rated as more gender-typed. Given that we observed these features, rather than experimentally manipulating them, it is possible that color, silhouette shape, or some other factor caused the observed pattern of ratings. Future work should orthogonally manipulate different features of avatar icons in order to test what features cause icons to be perceived as truly gender-neutral. This work could point to additional gender-neutral icons to be used in future interventions, possibly without generating the reactance observed here.

An additional limitation of Study 2 is that participants saw the icons for a relatively short amount of time. When given time to adjust, participants in the more female-typed condition may engage in system-change rather than the observed system-reification. Additionally, in order to amass enough female-typed icons in Study 2, we collected icons from both high and low trafficked websites. Although we both controlled for and measured differences in familiarity between conditions, it may be that some of the female-typed icons lacked sufficient prominence to inspire real change. Future studies should investigate alternative interventions to alter androcentric thinking while being alert to the system-stability threat found here. Such inventions could include longer exposure durations, repeated exposures, or more high profile female-typed exemplars.

Finally, a limitation of both Study 1 and Study 2 is the nature of the sample. Much of the work on androcentrism, including the present investigation, has been done in the United States (cf., Ng, 1990; Sczesny et al., 2016; Sczesny, et al., 2015). More work is needed to investigate the presence of androcentrism cross-culturally. Crosscultural work would be particularly appropriate in the context of social media websites' icons, as they are devoid of language and available to anyone with Internet access. 


\section{Conclusion}

Studies 1 and 2 provide evidence for deep-seated androcentrism. The online context seemingly allows for greater anonymity and, by-extension, gender-neutrality. Although gender-neutrality may create a reduction in some forms of gender bias (Dubrovsky et al., 1991), androcentrism persists. In Study 1, participants reported that overall, social media websites' default avatar icons seemed to be men. In Study 2, an intuitive approach to disrupt male-centric thinking by manipulating exposure to gender-typed icons instead had the opposite effect. Exposure to more female-typed icons caused political conservatives to be twice as likely to produce a man as a typical person. This kind of male-centric thinking has been shown to have serious, detrimental consequences, impacting both scientific accuracy and women's continued under-representation in certain domains (e.g., Cundiff, 2012; Stout \& Dasgupta, 2011). Thus, despite the potential for greater gender-neutrality online, social media websites icons' only reflect and perpetuate people's tendency to view men as being more normative or typical than women.

\section{Notes}

1. The results from Study 1 have been replicated using a version of the slider with man at 0 and woman at 100.

2. Results do not change in direction or significance level if the entire sample is retained; although note that this is still excluding the eight participants who indicated that they did not consider gender or that a typical person was transgender.

\section{References}

Aiken, L. S., \& West, S. G. (1991). Multiple regression: Testing and interpreting interactions. Sage.

American Psychological Association. (1978). Guidelines for nonsexist language in APA journals: Publication manual change sheet 2. Educational Researcher, 7(3), 15-17.

Bailey, A. H., \& LaFrance, M. (2016). Who counts as human? Antecedents to androcentric behavior. Sex Roles. Advance online publication. http://dx.doi.org/10.1007/s11199-016-0648-4

Beery, T. A. (1995). Gender bias in the diagnosis and treatment of coronary artery disease. Heart \& Lung: The Journal of Acute and Critical Care, 24, 427-435. http://dx.doi.org/10.1016/S0147-9563(95)80020-4

Bem, S. L. (1993). The lenses of gender: Transforming the debate on sexual inequality. New Haven, CT: Yale University.

Bem, S. L., \& Bem, D. H. (1973). Gender segregated want ads: Do they discourage female job applicants. Psychology and Social Issues. New York: Macmillan.

Broverman, I. K., Broverman, D. M., Clarkson, F. E., Rosenkrantz, P. S., \& Vogel, S. R. (1970). Sex-role stereotypes and clinical judgments of mental health. Journal of Consulting and Clinical Psychology, 34, 1-7.

http://dx.doi.org/10.1037/h0028797

Burke, S. E., \& LaFrance, M. (2016). Lay conceptions of sexual minority groups. Archives of Sexual Behavior, 45, 635-650. http://dx.doi.org/10.1007/s10508-015-0655-5

Cejka, M. A., \& Eagly, A. H. (1999). Gender-stereotypic images of occupations correspond to the sex segregation of employment. Personality and Social Psychology Bulletin, 25, 413-423.

http://dx.doi.org/10.1177/0146167299025004002

Connolly, I. (2016). Self and identity in cyberspace. In I. Connolly, M. Palmer, H. Barton, \& G. Kirwan (Eds.), An introduction to cyberpsychology (pp. 45-57). New York, NY: Routledge. 
Cundiff, J. L. (2012). Is mainstream psychological research womanless and raceless? An updated analysis. Sex Roles, 67, 158-173. http://dx.doi.org/10.1007/s11199-012-0141-7

Dasgupta, N., \& Greenwald, A. G. (2001). On the malleability of automatic attitudes: Combating automatic prejudice with images of admired and disliked individuals. Journal of Personality and Social Psychology, 81, 800814. http://dx.doi.org/10.1037/0022-3514.81.5.800

Dubrovsky, V. J., Kiesler, S., \& Sethna, B. N. (1991). The equalization phenomenon: Status effects in computermediated and face-to-face decision-making groups. Human-computer Interaction, 6, 119-146.

http://dx.doi.org/10.1207/s15327051hci0602_2

Duggan, M., \& Smith, A. (2013). Social media update 2013. Pew Research Center. Retrieved from http://www.pewinternet.org/2013/12/30/social-media-update-2013/

Dunn, O. J. (1961). Multiple comparisons among means. Journal of the American Statistical Association, 56, 52-64.

Eagly, A. H., \& Karau, S. J. (2002). Role congruity theory of prejudice toward female leaders. Psychological Review, 109, 573-598. http://dx.doi.org/10.1037/0033-295X.109.3.573

Eagly, A. H., \& Kite, M. E. (1987). Are stereotypes of nationalities applied to both women and men? Journal of Personality and Social Psychology, 53, 451-462. http://dx.doi.org/10.1037/0022-3514.53.3.451

Finnegan, E., Oakhill, J., \& Garnham, A. (2015). Counter-stereotypical pictures as a strategy for overcoming spontaneous gender stereotypes. Frontiers in Psychology, 6, article 1291.

http://dx.doi.org/10.3389/fpsyg.2015.01291

Forsyth, D. R., Lawrence, N. K., Burnette, J. L., \& Baumeister, R. F. (2007). Attempting to improve the academic performance of struggling college students by bolstering their self-esteem: An intervention that backfired. Journal of Social and Clinical Psychology, 26, 447-459. http://dx.doi.org/10.1521/jscp.2007.26.4.447

Gao, G. (2015). Why the former USSR has far fewer men than women. Pew Research Center. Retrieved from http://www.pewresearch.org/fact-tank/2015/08/14/why-the-former-ussr-has-far-fewer-men-than-women/

Gastil, J. (1990). Generic pronouns and sexist language: The oxymoronic character of masculine generics. Sex Roles, 23, 629-643. http://dx.doi.org/10.1007/bf00289252

Glick, P., \& Fiske, S. T. (2001). An ambivalent alliance: Hostile and benevolent sexism as complementary justifications for gender inequality. American Psychologist, 56, 109-118. http://dx.doi.org/10.1037/0003066X.56.2.109

Hallgren, K. A. (2012). Computing inter-rater reliability for observational data: An overview and tutorial. Tutorials in Quantitative Methods for Psychology, 8, 23-34.

Hamilton, M. C. (1991). Masculine bias in the attribution of personhood. Psychology of Women Quarterly, 15, 393402. http://dx.doi.org/10.1111/j.1471-6402.1991.tb00415.x

Hegarty, P., \& Buechel, C. (2006). Androcentric reporting of gender differences in APA journals: 1965-2004. Review of General Psychology, 10, 377-389. http://dx.doi.org/10.1037/1089-2680.10.4.377

Heilman, M. E., \& Eagly, A. H. (2008). Gender stereotypes are alive, well, and busy producing workplace discrimination. Industrial and Organizational Psychology, 1, 393-398.

Hellinger, M., \& Motschenbacher, H. (2015). Gender across languages (Vol. 4). Amsterdam / Philadelphia: John Benjamins Publishing Company. 
Hyde, J. S. (1984). Children's understanding of sexist language. Developmental Psychology, 20, 697-706. http://dx.doi.org/10.1037/0012-1649.20.4.697

Jost, J. T., \& Banaji, M. R. (1994). The role of stereotyping in system-justification and the production of false consciousness. British Journal of Social Psychology, 33, 1-27. http://dx.doi.org/10.1111/j.2044-8309.1994.tb01008.x

Jost, J. T., Banaji, M. R., \& Nosek, B. A. (2004). A decade of system justification theory: Accumulated evidence of conscious and unconscious bolstering of the status quo. Political Psychology, 25, 881-919.

http://dx.doi.org/10.1111/j.1467-9221.2004.00402.x

Jost, J. T., Glaser, J., Kruglanski, A. W., \& Sulloway, F. J. (2003). Political conservatism as motivated social cognition. Psychological Bulletin, 129, 339-375. http://dx.doi.org/10.1037/0033-2909.129.3.339

Kay, A. C., \& Friesen, J. (2011). On social stability and social change understanding when system justification does and does not occur. Current Directions in Psychological Science, 20, 360-364.

http://dx.doi.org/10.1177/0963721411422059

Kay, A. C., Jost, J. T., \& Young, S. (2005). Victim derogation and victim enhancement as alternate routes to system justification. Psychological Science, 16, 240-246. http://dx.doi.org/10.1111/j.0956-7976.2005.00810.x

Lai, C. K., Marini, M., Lehr, S. A., Cerruti, C., Shin, J. E. L., Joy-Gaba, J. A., . . Nosek, B. A. (2014). Reducing implicit racial preferences: I. A comparative investigation of 17 interventions. Journal of Experimental Psychology: General, 143, 1765-1785. http://dx.doi.org/10.1037/a0036260

Lambdin, J. R., Greer, K. M., Jibotian, K. S., Wood, K. R., \& Hamilton, M. C. (2003). The animal= male hypothesis: Children's and adults' beliefs about the sex of non-sex specific stuffed animals. Sex Roles, 48, 471-482. http://dx.doi.org/10.1023/A:1023567010708

Legault, L., Gutsell, J. N., \& Inzlicht, M. (2011). Ironic effects of antiprejudice messages how motivational interventions can reduce (but also increase) prejudice. Psychological Science, 22, 1472-1477.

http://dx.doi.org/10.1177/0956797611427918

Lenhart, A. (2015). Teens, social media, and technology, overview 2015. Pew Research Center. Retrieved from < href="http://www.pewinternet.org/2015/04/09/teens-social-media-technology-

2015/">http://www.pewinternet.org/2015/04/09/teens-social-media-technology-2015/

Miller, D. T., Taylor, B., \& Buck, M. L. (1991). Gender gaps: Who needs to be explained? Journal of Personality and Social Psychology, 61, 5-12. http://dx.doi.org/10.1037//0022-3514.61.1.5

Miller, H., \& Arnold, J. (2001). Breaking away from grounded identity? Women academics on the web. CyberPsychology \& Behavior, 4, 95-108. http://dx.doi.org/10.1089/10949310151088451

Miller, M. M., \& James, L. E. (2009). Is the generic pronoun he still comprehended as excluding women? The American Journal of Psychology, 122, 483-496.

$\mathrm{Ng}$, S. H. (1990). Androcentric coding of man and his in memory by language users. Journal of Experimental Social Psychology, 26, 455-464. http://dx.doi.org/10.1016/0022-1031(90)90069-X

Perrin, A. (2015) Social media usage: 2005 to 2015. Pew Research Center. Retrieved from http://www.pewinternet.org/2015/10/08/social-networking-usage-2005-2015/

Prentice, D. A. (1994). Do language reforms change our way of thinking? Journal of Language and Social Psychology, 13, 3-19. http://dx.doi.org/10.1177/0261927X94131001 
Reis, H. T., \& Carothers, B. J. (2014). Black and white or shades of gray are gender differences categorical or dimensional? Current Directions in Psychological Science, 23, 19-26. http://dx.doi.org/10.1177/0963721413504105

Roussos, G. \& Dovidio, J. F. (2016). Playing below the poverty line: Investigating an online game as a way to reduce prejudice toward the poor. Cyberpsychology: Journal of Psychosocial Research on Cyberspace, 10, article 3. http://dx.doi.org/10.5817/cp2016-2-3

Schneider, J. W., \& Hacker, S. L. (1973). Sex role imagery and use of the generic "man" in introductory texts: A case in the sociology of sociology. The American Sociologist, 8, 12-18.

Sczesny, S., Formanowicz, M., \& Moser, F. (2016). Can gender-fair language reduce gender stereotyping and discrimination? Frontiers in Psychology, 7, article 25. http://dx.doi.org/10.3389/fpsyg.2016.00025

Sczesny, S., Moser, F., \& Wood, W. (2015). Beyond sexist beliefs: How do people decide to use gender-inclusive language? Personality and Social Psychology Bulletin, 41, 943-54. http://dx.doi.org/10.1177/0146167215585727

Silveira, J. (1980). Generic masculine words and thinking. Women's Studies International Quarterly, 3, 165-178. http://dx.doi.org/10.1016/s0148-0685(80)92113-2

Stout, J. G., \& Dasgupta, N. (2011). When he doesn't mean you: Gender-exclusive language as ostracism. Personality and Social Psychology Bulletin, 37, 757-769. http://dx.doi.org/10.1177/0146167211406434

Switzer, J. Y. (1990). The impact of generic word choices: An empirical investigation of age-and sex-related differences. Sex Roles, 22, 69-82. http://dx.doi.org/10.1007/BF00288155

Vorauer, J. D., \& Sasaki, S. J. (2009). Helpful only in the abstract? Ironic effects of empathy in intergroup interaction. Psychological Science, 20, 191-197.

\section{Correspondence to:}

April H. Bailey

2 Hillhouse Ave

New Haven

CT 06511

United States

Email: april.bailey(at)yale.edu

\section{About authors}

April H. Bailey is a graduate student pursuing a PhD in Social Psychology at Yale University. Her research focuses on how another's gender impacts one's perceptions, judgments, and evaluations of them with a social cognitive orientation.

Marianne LaFrance is a Professor of Psychology and Women's Gender and Sexuality Studies at Yale University. Her work broadly focuses on the psychology of gender and the role of nonverbal communication.

(C) 2007-2016 Cyberpsychology: Journal of Psychosocial Research on Cyberspace | ISSN: 1802-7962 Faculty of Social Studies, Masaryk University | Contact | Editor: David Smahel 